\title{
TITLE:
}

\section{A speculation on the classification system of the Ctenophora}

AUTHOR(S):

Tokioka, Takasi

\section{CITATION:}

Tokioka, Takasi. A speculation on the classification system of the Ctenophora. Publications of the Seto Marine Biological Laboratory 2014, 42: 96-104

ISSUE DATE:

2014-04-10

URL:

http://hdl.handle.net/2433/185696

RIGHT: 


\title{
A speculation on the classification system of the Ctenophora
}

\author{
TAKASI TOKIOKA* \\ * [1913 - 2001]: Late professor emeritus of Kyoto University (Formerly, Seto Marine Biological Laboratory, Kyoto \\ University, Shirahama, Wakayama 649-2211, JAPAN). This manuscript was found in 2013.
}

\begin{abstract}
Standing on the close relationship between the Cestida and the newly found Lobatolampea tetragona Horita, the classificational arrangement of the higher taxa of the Ctenophora is revised by plotting respective taxa at their adequate sites in the flow of evolutionary changes, suspected from the variability seen in the gastric canal system and the feeding habit. In addition, some considerations are paid on the dissogony and the occurrences of large swarms of sterile adult forms in some species of the Lobata.
\end{abstract}

Keywords: Ctenophora, classification, gastric canal, feeding, dissogony, sterility

\section{Introduction}

At the discovery of a new ctenophore Lobatolampea tetragona by Horita (2000), I had a chance of studying again the taxonomy of this animal group to find the systematic position that can hold the mentioned species reasonably. Thus, I met the papers of Harbison and Madin (1982) and Harbison (1985). The systematic arrangement of 7 orders including 19 families shown in the former may be accepted as the latest one. The system is given as seen below:

1. Order Cydippida, including 5 families,

2. Order Platyctenida, including 4 familes,

3. Order Ganeshida, including a single family,

4. Order Thalassocalycida, including a single family,

5. Order Lobata, including 6 families,

6. Order Cestida, including a single family, and

7. Order Beroida, including a single family.

In this arrangement, dividing of ctenophores into two classes, Nuda to hold beroids and Tentaculata including all other forms, is removed, reflecting Komai's (1963) opinion pointing out the reducing tendency of the tentacle throughout the whole ctenophores and then the needlessness of retaining a class to separate beroids from other forms.

The situation of the Beroida at the end of the systematic arrangement might be regarded to show the thought that complete missing of the tentacle can be taken as a sign of the most advanced stage of the specialization.

There are two important comments made by these authors. In making detailed comparisons one another among the ctenophores to see the evolutionary way of progress, it is noted by Harbison (1985) that the issue of side branches from the meridional gastric canals concern the activity, thus the maintenance of metabolism in these body parts, and that the connection of meridional and pharyngeal canals along the oral margin is also 


\section{CLASSIFICATION SYSTEM OF THE CTENOPHORA}

related with the movement of the oral portion of the body, therefore such features cannot be adopted as the taxonomic criteria at the higher level of classification. The first part of his view is wholly agreeable, and the last half is also very plausible. In addition, Harbison and Madin (1982) seemingly intended to split the Cydippida into two groups, the one possibly containing three families: Haeckeliidae, Bathyctenidae and Lampeidae.

This idea is agreeable, too; although this is not reflected in the systematic arrangement shown previously. As many groups in the ctenophores release the cydippid larvae, it is obvious that the typical cydippids should occupy the starting position in the systematic arrangement. Nevertheless, somewhat modified forms with the tentacles and the pharyngeal canals reduced to some extent are placed at the top of the arrangement within the order Cydippida. This is different from what are kept in my mind. This might be a trace of the traditional thought as to the tentacle and the gastric canal system - the simpler, the more primitive. The morphological comparisons made by Harbison among the ctenophores are quite incomparable. However, as no accent is put in respective comparisons, it is rather not easy to learn any main string connecting the groups one another. In such a circumstance, it may be the easiest way to establish a new order, as the cases of the Ganeshida and Thalassocalycida, to give the new ctenophore, Lobatolampea tetragona, its final systematic situation.

This treatment was, however, checked by the fact that the new species resembles Cestum in the running course of a striking gastric canal. In both of these forms, the body is changed in each distal part of the pharyngeal axis to form respectively the wing in Cestum and the primitive oral lobe in Lobatolampea, and further the extension (see p. 101) of the subtentacular meridional canal is running through in each quadrant straight along the pharyngeal plane across respectively the wing or the oral lobe. Seemingly, it is not impossible that this resemblance involves some systematic significance. The deformation of the body in the pharyngeal axis in these two forms reminded me of the relation between the body movement and the functional structure of the gastric canal system. Thus, the reconsideration on the structure of the ctenophores was made in correlation with its function or rather the behaviour of the animal. Actually, this was attempted on the two main structures: the gastric canal system and the feeding habit in place of the tentacular apparatus.

\section{Important modification in the gastric canal system}

Throughout the ctenophores and also the medusoid coelenterates, the gastric canal system is the basic structure to maintain the metabolic function, therefore any kind of activity, in the animal body. In the typical cydippids in the ctenophores, comb-rows, the organ for locomotion and for carrying food in some body part, are supported respectively by meridional canals, the pharynx by pharyngeal canals, and the activity of tentacles by tentacular canals at their base. The aboral sense organ is also embraced by short canals. Thus, the structure of the gastric canal system can be discussed efficiently only in relation to the functional activities of the animal body. In the Cestida, Lobata and some others deformed in the body shape, the meridional canals are elongated into the deformed body parts wholly devoid of comb-rows to maintain the metabolism in those portions. Such an elongated part of the canal beyond the adoral end of the comb-row is treated here as the extension of the meridional canal that is defined for the convenience of description to the part of the canal approximately in the range running beneath the comb-row. Unusual elongation of the adradial canals occurs in Thalassocalyce and remarkable extension of the pharyngeal canals is observed in Cestum.

The standard design of the gastric canal system may be enough to maintain the life of smaller cydippids but some modification is required as mentioned above as to the extension of the canals to support larger forms. For the active movement of the body, that is accompanied with more solid consistency of the body, denser distribution of the gastric canals is indispensable. The active movement is represented in the ctenophores by creeping movement in the Platyctenida and predatory feeding in the Beroida; and in these the activity is supported by issue of side branches from the meridional canals, the branches are distributed in these groups so densely that the whole body is covered by some complicated racemose or areolar canal system. Side branches 


\section{TAKASI TOKIOKA}

or short diverticulae are issued from the pharyngeal and meridional canals in the bathyctenids in the Cydippida and also from the subpharyngeal meridional canals in Ocyropsis in the Lobata; predatory feeding is known in the latter and presumed in the former. Bathyctenia is coloured markedly as in the beroids and most platyctenids, and Ocyropsis has in each quadrant a prominent fleck coloured in sepia; probably such colouration may be a sign of the metabolism carried on there actively. Anyhow, the issue of diverticulae from the meridional canals occurs in different groups convergently reacting to the active functional pressure of the predatory feeding and thus quite independent from the evolutionary modification of the canal system.

The feature of the radial canals, inclusive of joining site between the radial and meridional canals, has been noted in the classification of the ctenophores. However, the differences seen in the mentioned feature are all regarded as belonging to the difference in grade. Missing of the perradial canal is nothing but the extreme shortening, joining of the adradial canal to the meridional canal at its aboral end may be the ultimate phase of the migration of the joining site towards the aboral pole.

Such features might be brought about by enclosure of the infundibulum in a small space just near the aboral end of the body. On the contrary, joining of the adradial canals to the respective meridional canals at the adoral end occurs, though rarely, as seen in Thalassocalyce and in the medusoid larval stage of Leucothea multicornis (Chun,1880), at the subtentacular meridional canal where the adoral end of the meridional canal is indicated by the junction between the comb row and the ctene (Chun, 1880); in all such cases the design of the canal system is accompanied with unusual elongation of the adradial canals.

These changes of the canal system in grade may be applicable to the taxonomic criteria at some classification levels, but cannot be used as the milestone in the evolutional change flow. Seemingly, only the running courses and the features of the extensions of the meridional and pharyngeal canals are changed in correlation with the shape and the movement of the body, along the flow of the evolutionary changes as suggested below.

(1) Formation of the circumoral canal. The canal is made of the extensions of the pharyngeal or subtentacular meridional canals, and the subpharyngeal meridional canals may join the formation in some forms. By formation of this canal along the oral margin, the activity in the mouth part may be enhanced, but at the same time, the animal will lose the ability to close the mouth as in the cydippids, and the expanded state will be fixed.

(2) Supporting of very flabby body portions by a single straight canal in each quadrant, that is the extension of the subtentacular meridional canal, running across the body along each side of the pharyngeal plane. The body is changed in each sagittal half to the wing in Cestum or to the primitive oral lobe in Lobatolampea, both are scarcely movable actively, showing merely slow swinging by waves.

(3) Extensions of the meridional canals are winding or looping as seen in the Lobata. This state seems to allow the animal some feeble movement. Rather active flapping of the oral lobes is observed in larger Ocyropsis, in which, however, short side branches are issued from the subpharyngeal meridional canals.

(4) Combination of the second (2) and the third (3) stages mentioned above. In Bathocyroe of the Labata, there is a straight canal on each side of the pharyngeal plane along the foot of the body core as seen in Lobatolampea. This canal is explained by the author of Bathocyroe as the extension of the pharyngeal canal. However, this is exactly corresponding to the similar structure found in Lobatolampea, in which the pharyngeal canal is ending blind near the level of the middle of the pharynx; therefore, this straight part of the canal system is better regarded as the extension of the subtentacular meridional canal. And, this feature may be accepted to manifest a case, in which some old feature of previous phylogenetical or ontogenetic stage is still remaining when the final design of the canal system is completed in the adult form. The canal system seems somewhat complicated and perplexing at a glance in Thalassocalyce, too. This feature is caused by extraordinary elongation of the adradial canals joining respectively the meridional canals at their adoral end as seen at the subtentacular meridional canal in the medusoid larval stage of Leucothea multicornis, and also by issue of a branch canal from near the base of the adradial canal towards the subtentacular meridional canals, that is connected to the adoral end of the subpharyngeal meridional canal via markedly winding course. 


\section{CLASSIFICATION SYSTEM OF THE CTENOPHORA}

\section{Feeding habit}

Plankton feeding using the tentacular apparatus is the basic feeding way in the Cydippida and the starting point of the feeding habit throughout the ctenophores. Plankters entangled by mucus secreted from the colloblasts on the primary tentacles are rubbed off at the entrance to the tentacular sheathes when the tentacles are contracted, carried along the subtentacular comb-rows to the oral aperture. Such a troublesome and time-consuming feeding way cannot be considered as effectual to keep the larger animal body with active movement, though the rotation or bending of the body may assist the food intake to some extent, or swift swimming may increase the food catch for some large-sized forms such as Mertensia. The improvement of the feeding habit is attained to some extent in the Cydippida by migration of the aperture of the tentacular sheathes to the oral margin to diminish the distance for food carrying on the subtentacular comb-rows and by allowing the animal to expand the oral aperture to make food receiving easier. The expanded state of the oral aperture will enable the animal to collect the food directly on the interior surface of the oral cavity (or the pharyngeal vestibule) by using mucus secreted there, and this might bring about the predatory habit in feeding as seen in the Haeckeliidae and probably in the Bathyctenidae, in the latter the meridional and pharyngeal canals bear side branches in correlation with the predatory feeding. The lampetids can spread the oral aperture very widely and catch prey animals by wrapping them with this spread oral portion.

It is noteworthy that the pharyngeal canal is reduced to some extent in the Haeckeliidae and Lampeidae. This modification might be related with the ability of the oral portion to expand or spread more freely. Further, the meridional canals are extended beyond the adoral end of the comb-rows into the eversible oral portion to support the active feeding movement in the Haeckeliidae, Lampeidae and the Bathyctenidae.

In Haeckelia rubra (Kolliker, 1853), the tentacle is wholly devoid of the side branches and the stem is armed with the nematocysts instead of the colloblasts, thus may be useful as the defence weapon. It is wanted with a great expectation to learn whether the type of the nematocysts found in this ctenophore is constant or variable. In the latter case, it is obvious that the nematocysts found in the tentacle are originated in the prey hydromedusae, while in the former case the nematocysts might be produced in this ctenophore and then regarded as a clue to explain the relationship between the Ctenophora and the Cnidaria, or it might be suggested that this ctenophore can select the prey hydromedusae so strictly.

No words are necessary to explain the predatory habit of the beroids that are wholly devoid of any trace of the tentacle. However, the tentacular apparatus is kept as far as the plankton feeding is retained. Even in such forms, a pair of the primary tentacles are [sic] apt to be reduced and replaced by the secondary tentacular apparatus consisting of two pairs of tentacles, a pair being issued from earch [sic] tentacular base so as a single creeping tentacle stem is existing in each quadrant. The stem is running along the foot of the body core and then along the oral margin, and furnished with side branches. The distinction between the proximal half of the stem along the body core and the distal half along the oral margin is obscure in Cestum or Kiyohimea of the Lobata, both strongly compressed in the tentecular [sic] axis. This structure is to maintain the food collecting capacity on the interior surface of the oral lobes, the widely spread oral cavity in those forms. The formation of the secondary tentacular system might be effectual even a little to enhance the food collecting efficiency, that is however still very low, because the foods caught by tentacles are carried to the pharyngeal opening along the long way of the ciliated grooves running with the tentacle stems, though much more foods might be obtained in the proximal portion of the tentacles furnished with somewhat longer side branches than in the distal portion as seen in Lobatolampea or Kiyohimea. Probably, the secondary tentacular apparatus is formed in relation to the enlargement of the animal body. With the aquirement [sic] of the predatory capacity, both the primary and the secondary tentacles will wholly disappear as seen in adult Ocyropsis.

Further, even in the Platyctenida, that retains the primary tentacles steadily, the tentacles are reduced each to a tuft of the tentillae as seen in creeping Savangia, or side branches are completely lost in sedentary Tjalfiella. This is not strange, as the most important role of the tentacle is to secrete the mucus to catch foods. 


\section{TAKASI TOKIOKA}

Anyhow, the reduction of the tentacles is occurring convergently in different groups of the ctenophores, and thus may be put outside the flow of the evolutionary changes.

\section{Evolutionary modification flow and classification of the ctenophores}

Uniting the tendencies seen in the series of changes in the gastric canal system and in the gradual reduction of the tentacular apparatus, the following speculation might be born as to the evolutionary classification of the ctenophores.

Starting from the basic type of the Cydippida, a group, newly named Lampeida, was formed. The group might be large and included many elastic forms, in which the tentacular bulbs are migrated towards the oral side and the sheaths, when present, open on the oral margin which can be expanded or widely spread, and the tentacles themselves may be reduced with the increase of predatory feeding. The meridional canals are extended beyond the adoral end of the comb-rows to the eversible oral portion and the pharyngeal canals are reduced to some extent in the forms capable of predatory feeding. In the plankton feeding forms the primary tentacles are retained steadily. The circumoral canal is not yet formed.

This large group dispersed in three directions, leaving only a small number of species classified today into three families; Lampeidae, Haeckeliidae and Bathyctenidae. Two of the three directions are pelagic, while the remaining one is concerned with the sedentary platyctenids through the stage of Ctenoplana, all with the oral portion widely spread in the tentacular axis; the whole body is penetrated with finely ramified side branches from the meridional canals, which are intersecting to form the network to support the creeping movement of the animal; the primary tentacles are reserved as the feeding apparatus, although in Savangia they are reduced to the bundles of tentillae.

One in the pelagic direction is for the Beroida, probably arisen from some form around the Haeckeliidae and Bathyctenidae, while most part of the Lampeida might be changed in the course towards the large group of the Lobata. The first step in this course is the formation of the circumoral canal as well as in the Beroida, and then comes the improvement of the tentacular apparatus by formation of the secondary tentacular system as seen in most forms on the way from Lampeida to Lobata, all being plankton feeders. Replacement of the primary tentacles by secondary tentacles is complete in such a form as Lobatolampea. The secondary tentacular system is undescribed in Ganesha and Thalassocalyce.

Four forms are found between the Lampeida and the Lobata that is characterized most prominently by (1) formation of the oral lobes, (2) existence of the auricle, (3) winding and looping of the extensions of the meridional canals and (4) the joining site between the adradial and meridional canals, inclusive of missing of the perradial canals. Availing these four characteristics as a kind of measure, it was tried to find more reasonable systematic situations for the species of the Ganeshida, Cestida, Lobatolampea and Thalassocalyce left between the Lampeida and Lobata. Of the four characteristic features of the Lobata given above, the last one (4) is not absolute as seen in Deiopea of the Bolinopsidae, in which the joining site of the adradial canal to the subtentacular meridional canal is a littele [sic] moved orally from the aboral end of the canal. Ganeshia resembles the lobateans only in the feature of the radial canals and in the joining site between the adradial and meridional canals. Therefore, the Ganeshida is placed most remotely from the Lobata. Thalassocalyce shows neither any sign of formation of the oral lobes nor auricles, but the design of the courses of the branches from the extensions of the meridional canals and the adradial canals resembles closely that of the medusoid larval stage of Leucothea multicornis. Thus, it is possible to regard this form as an ancestral one related to Leucothea or a kind of the neotenous product, and to place it reasonablly [sic] most nearly to the Lobata.

Lobatolampea shares the oral lobes though in a primitive state, in addition it is provided with the ctenes, the precursory structure of the auricle, seen in the medusoid larval stage of Leucothea multicornis. The extensions of the subtentacular meridional canals, traversing the body straight along the pharyngeal plane are 


\section{CLASSIFICATION SYSTEM OF THE CTENOPHORA}

seen actually in Bathocyroe of the Lobata. Therefore, this feature might imply an eminent phylogenetic significance. In other aspects, however, the canal system is quite similar to that of the lampeids. For this reason, Lobatolampea is placed in the site more distant from the Lobata than Thalassocalyce. The Cestida resembles closely Lobatolampea in having the straight canals, the extensions of the subtetacular meridional canals, traversing the wing. In the cestids, the body is so much compressed in the tentacular axis and extended markedly in the pharyngeal axis to form the wings in place of the oral lobes. Then, the canal system is changed in correlation with this striking deformation of the body. The cestids might be regareded as being related to the Lobata through the intermediary of Lobatolampea and thus plotted between Ganeshia and Lobatolampea in the flow of the evolutionary changes. Seeing through these intermediate forms between the lampeids and lobateans, it is noteworthy that only a single or two of the four characteristic features (1-4) of the Lobata are appearing in respective groups quite independently. This may lead the thought, at the present level of knowledge, to the probability that at least three of the four groups excluding Thalassocalyce are originated polyphyletically from the ancient large Lampeida, quite independently rather than being born successively in the order on the way from the lampeids to the lobateans. The final decision concerning the above-mentioned explanation will be made possible by discovery of other new forms of different types and further studies of the life history of respective species of the Lobata, as the present speculation owes much to the finding of Lobatolampea and Chun's ontogenetical description of Leucothea.

In the present speculation, three forms (the Ganeshida, Cestida and Lobatolampea) are gathered in a newly established order, the Prelobata, as they share respectively at least one of the four main charecteristics [sic] of the Lobata, representing within the new order respectively the suborders, Ganeshiae, Cestiae and Lobatolampetiae. While, Thalassocalyce is regarded as seen in previous papers to represent an independent order newly named Protolobata instead of Thalassocalycida to show its systematic position more clearly.

In conclusion, the groups in the Ctenophora may be arranged systematically as shown in the following diagramme and the list.

\section{CYDIPPIDA}
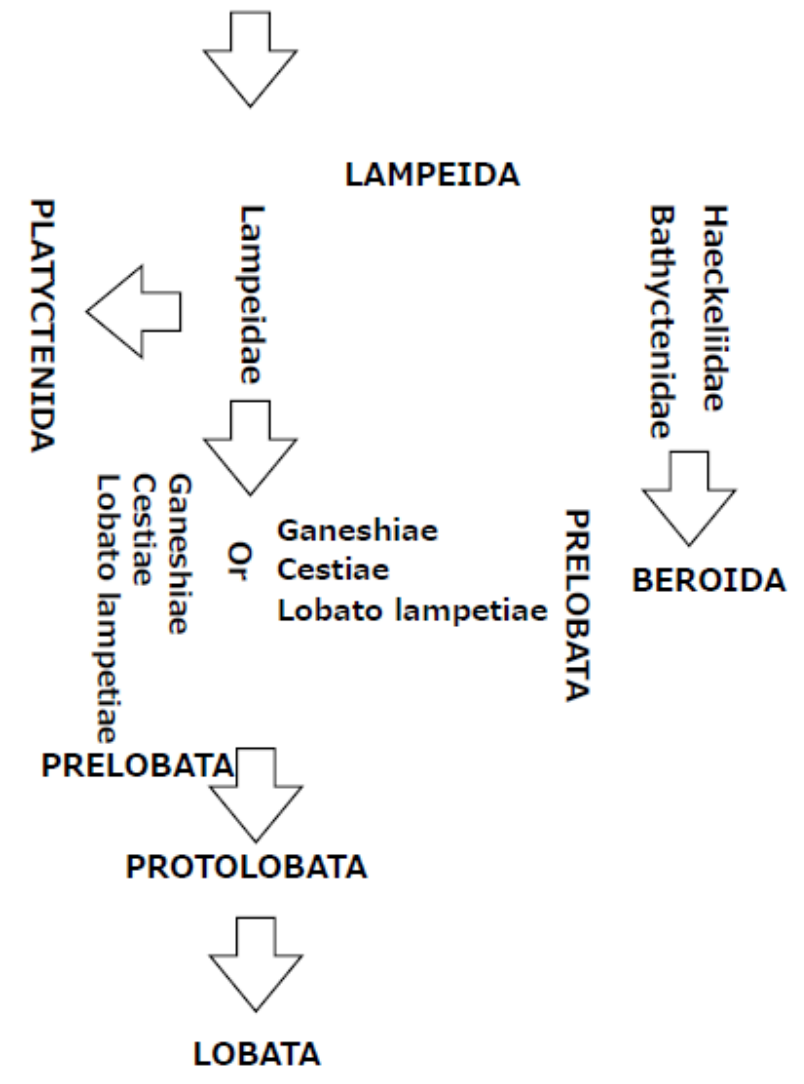


\section{TAKASI TOKIOKA}

It is difficult to express the diagramme in a series of the names of respective groups. From the view point of the phylogenic relationship, the Beroida and Platyctenida may be put aside the Lampeida, as so treated here, but at the tail of the list from the view point of the specialization or the advancement of modification.

1. Order Cydippida, including 3 families, Pleurobranchiidae [sic], *Euplokamidae and Mertensiidae. *established for Euplokamis dunlapea Mills, 1987

2. Order Lampeida, including 3 families, *Haeckeliidae, Bathyctenidae and Lampeidae. *inclusive of Dryodoridae,

3. Order Beroida, including a single family,

4. Order Platyctenida, including 4 families,

5. Order Prelobata

Suborder 1. Ganeshiae, including a single family,

Suborder 2. Cestiae, including a single family,

Suborder 3. Lobatolampetiae, including a single family, Lobatolampeidae,

6. Order Protolobata, including a single family, Thalassocalycidae,

7. Order Lobata, including 6 families: Deiopeidae is included in Bolinopsidae.

The Beroida is moved to aside the Lampeida after long hesitation, through understanding by myself the process that the morphology of lower invertebrates is apt to be changed rather reasily [sic] reacting to the functional pressure in the living habit, inclusive of the embryonal development as the animals have to achieve their adult morphology in the limited time-span. The more actively the animals move, the more greatly and rapidly proceeds the modification. In the Ctenophora, the predatory feeding and creeping movement may represent the highest activity. This understanding seems to justify the revised situation of the Beroida.

In the Lobata, the family Bathocyroidae may be better treated as the most primitive one as being suggested by the body shape, markedly compressed in the oral-aboral axis, wide lobe-like shape of the auricles and retaining a straight canal traversing the body along each side of the pharyngeal plane as in Lobatolampea so treated already by Wrobel and Mills (1998).

\section{Some considerations on the occurrence of rare species}

There remains still a very strange phenomenon before the speculation is closed, this concerns the fact that many taxa at different levels are represented by only a single to a few extremely rare species. Unfortunately, these species might be endangered to extinction.

While I stared at the illustrations of the typical cydippid forms, it was noticed unexpectedly that the nutrition gained by animals is divided to respective body organs very precisely, as shown by the design of the gastric canal system; to 8 meridional canals for supporting the comb-rows (locomotive organ), 2 pharyngeal canals for the pharynx (alimentary organ), 2 tentacular canals distally embracing the tentacular base (feeding apparatus) and a single infundibular canal to support the aboral sensory organ; and there are no other excess canals.

The meridional and pharyngeal canals are similar in the thickness and length, the tentacular canals are much shorter but a little thicker and connected directly to the perradial canals, and the infundibular canal is short but issued directly from the infundibulum. Supposing that the amount of nutrition flowing into the respective ones of the last three canals, two tentacular and a single infundibular, may be roughly similar to that delivered to respective meridional and pharyngeal canals, as the former are connected much more closely to the infundibulum and therefore the degree of refleshment [sic] of the canal contents might be much higher 


\section{CLASSIFICATION SYSTEM OF THE CTENOPHORA}

than in the latter, it is estimated that the nutrition or the energy is divided into 13 , and $8 / 13$ is used for the locomotive activity of the comb-rows.

Needless to mention that some part of the nutrition is flowing into the mesogloea through the rosettes. However, the share of $8 / 13$ seems unusually high. The meridional canals are extended beyond the adoral margin of the comb-rows into the body portions formed by spreading of the oral margin and then into the wing (in cestids) or the oral lobe (in lobateans), though the extensions can only support there the existence of the enlarged body portion but are insufficient to give the wings or oral lobes any active movement, except in Ocyropsis. In pelagic animals, usually the locomotive movement will aid the feeding habit to some extent. In the Ctenophora, however, the comb-rows are seemingly effective only to maintain the correct orientation of the body, except in Mertesia which can swim rather swiftly and this allows the animal to collect much larger amount of food and then to increase the body size. Certainly the increase of the body size may be effective to some extent to avoid the predation by other animals, but only the enlargement of the body without any recognized activity cannot be beneficial to the living way of this animal group. Further, there is no sign of any structure for reproduction, for instance such as some thickening of the wall cells in the meridional canals for the storage of nutrition for the formation of the gonads. The animals seem proceeded towards the increase of the body size by formation of the wings or oral lobes, without any effective improvement in the feeding habit and the dividing rate of energy.

Thus, the significant part of the energy obtained by low effective feeding habit is used by the activity of the comb plates, leaving the formation of gonads untouched.

The phenomenon of the dissogony is known in this animal group as being noted in the Lobata, and it is stated as in the Leucotheidae, that "all larval stages may develop gonads under certain conditions (Harbison and Madin, 1974, p. 714). It is guessed that the dissogony might be introduced in the Ctenophora by unusually higher share of the nutrition to the locomotive organ, under the conditions of the insufficient effectiveness of the activity of the comb-rows and the tentacular apparatus to induce the enlarged body portion any activity useful to the living habit. Probably the body size, when the first reproduction is carried, may be regarded as adequate for the animals, to support safely their living way inclusive of the reproduction. The "conditions" stated by Harbison and Madin as to the Leucotheidae might mean some heavy catch of food rich enough for the formation of the gonads. The increase of the body size towards the Lobata might be a kind of overgrowth. The dissogony might be a phase on the way returning to the smaller, bioeconomically adequate body size; the opposite way from smaller to larger size is unreasonable as far as no improvements of the locomotive organ and the feeding apparatus are achieved. Really, in the present circumstances, it is impossible to expect the store of nutrition for the format of the gonads in large sized adult forms. The larger the body, the worse the conditions for reproduction. The appearances of huge specimens of Castum or the large swarms of the sterile adult forms in some kinds of the Lobata seem to show above-mentioned relationship clearly. Those might be expressed as a kind of the ghosts in the sea. It is known in some marine animals a tendency that the growth of the body might be allowed in the state of non formation or inmaturity [sic] of the gonod [sic]. It is not impossible that an unfavourable circulation between the cause and result might have been established already in some adult forms of the ctenphores [sic]. The alternation of the feeding habit from plankton feeding to the predatory feeding, accompanied with the active movement of the body, inclusive of the stronger effect of the com-rows, is certainly an important improvement for respective individuals. However, the main objects of the food are consisting of the forms of the same animal group, thus this is a kind of the cannibalism, leading to the suicide of the species. The liberation from the locomotion by comb plates is attained in the Platyctenia especially notably near the end of the specialization towards the sedentary, nearly sessile, life, represented by Lyrocteis and Tjalfiella. However, the vitality and the elasticity of the animals are lost in those forms around the apex of the series of the evolutionary specialization. Seemingly, all are too late for this animal group, and this might be correlated with the independent appearances of a significant number of rare species. 


\section{TAKASI TOKIOKA}

\section{Acknowledgements}

In preparing the manuscript for publication, I owe much to Prof. T. Nishikawa of Nagoya University and also to Mrs. M. Okita at the Library of the Seto Marine Biological Laboratory, my hearty thanks are due to them for their kindness.

\section{References}

Harbison, G. R. 1985. On the classificaiton [sic] abd [sic] evolution of the Ctenophora. In, Conway Morris, S., George, J. D., Gibson, R. and Platt, H. M. (eds.) The Origins and Relationships of Lower Invertebrates. The Systematic Association, Special volume no. 28, Clarendon Press, Oxford, pp. 78-100.

Harbison, G. R. and Madin, L. P. 1982. Ctenophora. In, Parker, S. P. (ed.) Synopsis and Classification of Living Organisms. Vol. 1, McGraw-Hill, New York, pp. 707-715.

Horita, T. 2000. An undescribed lobate ctenophore, Lobatolampea tetragona gen. nov. \& spec. nov., representing a new family, from Japan. Zoologische Mededelingen, 73, 457-464.

Komai, T. 1963. A note on the phylogeny of the Ctenophora. In, Dougherty, E. C. (ed.) The Lower Metazoa: Comparative Biology and Phylogeny, University of California Press, Berkley, pp. 181-188.

Madin, L. P. and Harbison, G. R. 1978. Thalassocalyce inconstans, new genus and species, an enigmatic ctenophore representing a new family and orader [sic]. Bulletin of Marine Science, 28, 680-687.

Madin, L. P. and Harbison, R. G. [sic] 1978. Bathocyroe fosteri gen. nov., sp. nov. : A mosopelagic [sic] ctenophore observed and collected from a submersible. Journal of the Marine Biological Association of the United Kingdom, 58, 559-564.

Wrobel, D. and Mills, C. 1998. Pacific Coast Pelagic Invertebrates: A Guide to the Common Gelatinous Animals. Sea Challengers and Monterey Bay Aquarium, Monterey, 108 pp.

\section{Additional reference}

The following article is referred in the section, "Important modification in the gastric canal system", but not cited in the "References".

Chun, C. 1880. Die Ctenophoren des Golfes von Neapel und der angrenzenden Meeres-Abschnitte. In Zoologischen Station zu Neapel (ed.) Fauna und Flora des Golfes von Neapel, Vol. 1, Wilhelm Engelmann, Leipzig, 313 pp., 18 pls. 